Publicación semestral. ISSN 2215-4906

Volumen 79 - Número 1

Revista de las artes Julio - Diciembre 2019

\title{
Iván César Morales Flores, Identidades en proceso. Cinco compositores cubanos de la diáspora (1990-2013)
}

\author{
Ailer Pérez Gómez
}

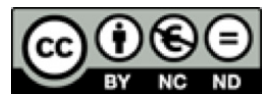

Esta obra está bajo una licencia Creative Commons Reconocimiento-No comercial-Sin Obra Derivada 
Reseñas

\title{
Iván César Morales Flores, Identidades en proceso. Cinco compositores cubanos de la diáspora (1990-2013)
}

\author{
Ailer Pérez Gómez ${ }^{1}$ \\ Centro de Investigación y Desarrollo de la Música Cubana \\ Cuba
}

Recibido: 31 de marzo de 2019 Aprobado: 1 de junio de 2019

\begin{abstract}
El fenómeno de la migración es inherente a la historia de la nación cubana. Sus matices y complejidades en el reciente tránsito entre los siglos XX y XXI marcan los caminos de indagación y reflexión, no exentos de controversia y polémica, que llevaron al musicólogo cubano Iván César Morales Flores (Pinar del Río, 1975-) a obtener el Premio de Musicología Casa de las Américas (2016), uno de los principales reconocimientos para la disciplina a nivel latinoamericano. De este resultado deriva la publicación del ensayo Identidades en proceso. Cinco compositores cubanos de la diáspora (1990-2013), con el cual se aproxima a dicho fenómeno y sus fuertes implicaciones en el ámbito de la composición académica en Cuba. Este es un tópico en el que la musicología cubana no indaga aún de forma sistemática, quizás por su cercanía en el tiempo, quizás por la sensible connotación que tiene, tanto para los cubanos que se mantienen en el país como para los que radican en el exterior.
\end{abstract}

En ese sentido, la investigación de Iván César Morales abre una brecha que debiera ser observada con interés, amén del dictamen de un jurado que significó en su propuesta, el análisis "competente de aspectos de la música académica contemporánea dentro de la perspectiva de uno de los fenómenos más complejos que vive América Latina: la migración y su impacto en la reconstitución de identidades y subjetividades" (Acta de Premiación, Premio de Musicología Casa de las Américas, 2016, párr. 2).

Específicamente en Cuba, a partir la década de 1990 se incrementó el éxodo de creadores formados en los predios del entonces Instituto Superior de Arte, núcleo de lo que puede identificarse como "escuela cubana de composición". Impulsados por motivaciones

1 Investigadora agregada en el Centro de Investigación y Desarrollo de la Música, Cubana y Profesora auxiliar en la Facultad de Música, Universidad de las Artes (ISA). Máster en Música, mención Musicología por la ISA, Cuba. Correo electrónico: ailerperez@cubarte.cult.cu 
Iván César Morales Flores, Identidades en proceso.

Reseñas

Cinco compositores cubanos de la diáspora (1990-2013)

económicas, sociales, políticas o ideológicas, este grupo creciente se ha ido instalando en nuevos espacios geográficos y socioculturales. Este hecho pone en juego la cuestión de la "pertenencia cultural", al plantear la disyuntiva entre ser consecuente con una formación musical de "estrato local" y las necesidades y exigencias de replanteo y adaptación ante un nuevo "entorno de acogida". Inmersos en estos procesos, dichos creadores se convierten "en nudo representativo de la amplia red que se conoce en la actualidad como diáspora cubana" (Morales, 2018, p. 11).

Es justamente este el concepto en el cual se ampara el autor, para comenzar a reflexionar acerca de las múltiples complejidades que el fenómeno imprime a la totalidad de la creación académica contemporánea en Cuba, y lo entiende, a la luz de su investigación, como "el total de espacios habitados por la emigración cubana desde la década de los noventa hasta el presente y que, a diferencia de la categoría exiliado, no representa necesariamente a un posicionamiento político opositor, aunque tampoco lo excluye" (Morales, 2018, p. 12). Esta línea de pensamiento se articula con el concepto de identidad, en lo que define como "identidad diaspórica": "la cualidad de rasgos relacionales de un individuo o conjunto de ellos quienes, en permanente proceso de cambio, hacen posible su identificación [...] y comunicación con realidades socioculturales concretas" (Morales, 2018, p. 12).

Esta perspectiva resultó entonces la más apropiada para entender los complejos espacios simbólicos generados por las obras de los compositores cubanos de la diáspora, donde se observan múltiples cruces e hibridaciones de rasgos culturales que derivan en particulares discursos de "intermediariedad-frontera", identificados y analizados por Morales, a partir de observar

los procesos de cambio y continuidad que operan en los discursos creativos de estos compositores cubanos de los últimos tiempos, representativos de esa expresión de adaptabilidad y negociación identitaria que, indefectiblemente caracteriza el hacer musical de la diáspora de la Isla" (Morales, 2018, p. 12).

De ese grupo de compositores elige cinco, cuyas trayectorias vitales y profesionales, desde sus individualidades y puntos comunes, le permiten entender procesos de adaptación y transformación diversos. Ileana Pérez Velázquez (1964-), Louis Aguirre (1968-), Eduardo Morales-Caso (1969-), Keyla Orozco (1969-) y Ailem Carvajal (1972-), emergen como indiscutibles casos de estudio, no solo por el impacto de su música en el ámbito creativo contemporáneo, sino porque en sus catálogos autorales se manifiestan

los tres ejes fundamentales que marcan la creación musical de esta generación: a) las diferentes formas de relacionarse con la música cubana y la escuela compositiva de la Isla; b) la incorporación de otras fuentes de música tradicional y popular ... y c)

ESCENA. Revista de las artes, 2019, Vol. 79, Núm. 1 (julio-diciembre), pp. 340-446 
la adopción de lenguajes y técnicas compositivas en auge en el espacio músico-cultural de sus nuevos entornos de residencia (Morales, 2018, pp. 12-13).

Estas regularidades observadas en el universo de compositores, formados desde finales de la década de 1980 y la de 1990, marcan una dirección concreta en las búsquedas y reflexiones del musicólogo, al precisar un orden de mirada en el análisis musical del repertorio producido por los sujetos de su estudio, tanto en su etapa cubana como residiendo en otra nación. De ahí que el autor reconozca el abordaje de la música no solo como estructura sonora, sino como "texto simbólico, intertextual" donde es posible identificar las múltiples referencias derivadas del permanente proceso de hibridación a que se someten en el ejercicio de la creación. Todo ello desde en una perspectiva de análisis musical abierto que articula diversos procedimientos en función de desentrañar las especificidades, rasgos y comportamientos reunidos en el conjunto de la obra de los compositores.

Vale resaltar en ese sentido cómo se conjugan herramientas validadas en el pensamiento de la teoría musical de occidente, habituales para el análisis de repertorio contemporáneo, como los pitch class set desde la perspectiva de Allen Forte, con propuestas que parten del más sólido pensamiento musicológico cubano, como el concepto de "franjas tímbrico-funcionales" planteado por Argeliers León, o la proyección de las "franjas o espacios de acción e interacción" formuladas por Danilo Orozco, en ambos casos para analizar comportamientos reconocidos dentro de un "modo de hacer cubano".

Sobre esta base metodológica, Iván Cesar Morales Flores sitúa el fenómeno de la composición académica cubana y la migración hacia el extranjero, de sujetos asociados a ella, en los complejos escenarios de la diáspora cubana. Para ello, en primer término, revisa el pensamiento en torno a la "diáspora intelectual cubana en el cambio de siglo", en un capítulo inicial donde relaciona documentadamente los principales discursos político-ideológicos e imaginarios resultantes de su producción simbólica, así como los móviles migratorios, desde una postura todo lo objetiva posible, asumiendo que el investigador mismo es también un sujeto de esa diáspora. Este resulta el "introito" apropiado para enunciar y fundamentar las categorías sobre las que se sustenta el ensayo, y las relaciones entre ellas: diáspora e identidad. Aquí asume el reto y el riesgo que implica el uso de definiciones y términos migrantes -muchas veces contradictorios en sus enfoques- para consolidar la plataforma teórica del estudio.

En ese sentido, las categorías empleadas para entender las "identidades en proceso" de los compositores estudiados, parten del referente de las figuras de la identidad moderna enunciadas por el teórico cultural Lawrence Grossberg: diáspora (insiste en la fluidez e intencionalidad histórico-espacial de definir la identidad); différance (lo subalterno como ambigüedad o inestabilidad inherente / un otro exótico); hibridez (imagen 
Iván César Morales Flores, Identidades en proceso.

Reseñas

Cinco compositores cubanos de la diáspora (1990-2013)

de intermediariedad que construye un espacio propio consciente de la movilidad, la incertidumbre y multiplicidad de cruces), y fragmentación (multiplicidad de identidades y posicionamientos) (Morales, 2018, p. 48)

El segundo capítulo, "Creación musical y revolución ideoestética en Cuba: los maestros de composición del ISA (1980-1990)", intenta sistematizar la información acerca del entorno académico y musical en el que los compositores de la diáspora recibieron esa primera orientación creativa, como legado de su país de origen y de los maestros que les acompañaron, también "protagonistas de la composición académica cubana y latinoamericana" en más de medio siglo de historia. Harold Gramatges (1918-2008), Carlos Fariñas (1934-2002) y Roberto Valera (1938), representan los tres perfiles esenciales que definen las principales influencias pedagógicas, ideoestéticas y compositivas recibidas por los jóvenes compositores de la diáspora, en su diálogo con el contexto habanero de partida, radicado en el Departamento de Composición del ISA.

Por otro lado, la perspectiva del trabajo en cuanto a la disyuntiva de pertenencia que han enfrentado los sujetos de estudio se traduce en la propia concepción de los cinco capítulos dedicados al análisis de sus individualidades, los que muestran una estructura similar en esencia, que permite hacer balances del desempeño de los creadores en la socorrida relación unidad - diversidad. Cada sección comparte el cotejo de referentes factuales que informan acontecimientos significativos de sus trayectorias vitales, académicas y profesionales dentro y fuera de Cuba, y se conjugan con el análisis de comportamientos de las estructuras musicales, referentes y móviles creativos en obras escogidas de sus catálogos, asumiendo para ello variables ajustadas a las particularidades de cada caso, pero siempre transversales al concepto de identidad diaspórica y las formas en que este puede entenderse desde las obras.

De ese modo se plantea un doble ejercicio discursivo, enunciado desde el propio título, al sintetizar la esencia de su pensamiento musical, siempre reconociendo su dinámica y permanente sentido de construcción, expresados a través de la "multiestilística y nueva expresividad" de lleana Pérez Velázquez, la "poética y reencuentro del legado hispánico" en Eduardo Morales Caso, los permanentes "ironía y diálogo intercultural" en el catálogo de Keyla Orozco, el sentido de "insularidad" y necesidad de "reinvención" en Ailem Carvajal, y el "neoafrocubanismo" y "ritualidad sincrética" de Louis Aguirre. Con estos análisis el investigador puede sustentar la idea de un posicionamiento que se desmarca de los extremos opuestos que caracterizaron la producción intelectual de los noventa en Cuba, puesto que

"en el orden ideológico, sus discursos musicales no persistieron ni en los contenidos políticos ... a favor del ideal revolucionario socialista de los años sesenta y setenta ni en el discurso crítico, alternativo, brotado de la realidad sociopolítica de los noventa. 
Sus obras de estos años de formación académica e iniciación profesional se inclinaron fundamentalmente hacia una estética de nueva expresividad, desentendida tanto de complejidades, como de posicionamiento de vanguardia y actitudes políticas significativas (Morales, 2018, p. 374).

Al mismo tiempo, identifica entre los rasgos significativos de la producción musical académica cubana de los años noventa comportamientos que reflejan el momento histórico y sociocultural, con una tendencia a la claridad estructural, lineal y expresiva del discurso. Por otro lado, a pesar de la dispersión de localizaciones en la etapa creativa -de maduración y desarrollo profesional- en la que se establecen en la diáspora cubana -desde Nueva York, Madrid, Ámsterdam, Parma y Aalbor- y las estrategias específicas que han debido asumir en su constante adaptación y resistencia, pueden identificarse resultantes comunes en cuanto a "la escisión de una identidad cultural de origen, la doble conciencia entre la asimilación/conciliación y el retorno utópico, y la (re)territorialización espiritual, corporal y artística de un espacio propio fuera del suyo" (Morales, 2018, p. 377). El rigor y oficio en el manejo de las fuentes documentales y testimoniales, así como el nivel teórico-metodológico sobre el que se sustenta el estudio de Morales son algunos de los atributos que le conducen a sostener un discurso sólido, aunque no exento de riesgo y necesidad de futuros replanteos ante la naturaleza dinámica y cambiante de los fenómenos que analiza.

Sin embargo, se extraña el diálogo con algunos de los resultados -relativamente recientes- de la academia musicológica cubana, en los cuales se explora el tópico de la migración y su impacto en escenas musicales diversas, como es el caso de la generada por el desempeño de jóvenes jazzistas, así como los procesos y resultados de síntesis musicales y culturales que de ellos derivan. De cualquier modo, es innegable que con este trabajo el autor llega a un punto de madurez y consolidación de su producción musicológica, que remite indefectiblemente a su origen formativo en la academia musical cubana, al tiempo que muestra el crecimiento condicionado por su residencia y desempeño profesional en el continente europeo. En definitiva, el investigador, desde su posicionamiento como intelectual cubano que reflexiona más allá de las fronteras geográficas de la nación, comparte la circunstancia de sus coterráneos compositores, quienes, con sus obras, "tienden puentes de inserción, diálogo y entendimiento entre dos espacios de una misma isla (local/global) que coexiste en el vórtice de sus fronteras culturales e identitarias"(Morales, 2018, p. 389).

\section{Referencia}

Acta de Premiación. (2016). Premio de Musicología Casa de las Américas 2016. Recuperado de http://www.casa.cult.cu/premios/musicologia/actaXV.php?pagina=XV

Morales Flores, I. C. (2018). Identidades en proceso. Cinco compositores cubanos de la diáspora (1990-2013). La Habana: Fondo Editorial Casa de las Américas.

ESCENA. Revista de las artes, 2019, Vol. 79, Núm. 1 (julio-diciembre), pp. 340-446 